\title{
ECONOMIC ASSESSMENT OF RECOVERY OF ALUMINUM RADIATOR BY GAS-DYNAMIC SPRAYING
}

\author{
Sergey Strebkov, Andrey Bondarev, Alexey Slobodyuk \\ Belgorod State Agricultural University named after V. Gorin, Russia \\ serwastr@gmail.com, av.bondarev@gmail.com, aspl22@yandex.ru
}

\begin{abstract}
Restoration of the working condition by replacing parts purchased from an authorized dealer makes repair very expensive due to the manufacturer's monopoly. The increase in the maintenance costs is directly proportional to the cost of equipment and, for some tractors, can amount to several hundred thousand rubles. An analysis of the cost of repairing foreign agricultural equipment shows, on average, a double reassessment of the cost of spare parts in the overall structure of the cost of restoration.

The article is devoted to development and justification of the economic feasibility of the technology of restoring failed aluminum radiators of the John Deere tractor. A distinctive feature of the proposed technology is the use of gas-dynamic spraying, which ensures the restoration of the tightness of the radiator, made of thin-walled aluminum parts, and having a form that is difficult to perform by traditional technological operations. As a result of the experimental studies, optimal process parameters were determined. The installation angle of the nozzle installation for gas-dynamic spraying and the distance from the nozzle to the sprayed surface were determined, providing, along with acceptable mechanical properties of the re-applied coating, sufficient performance. Thus, the study found that the use of a supersonic sputtering device to restore the aluminum radiator RE226366 of the JOHN DEERE 7830 tractor makes it possible to fully restore the performance of the part with high profitability and payback period of additional capital investments of 0.33 years. Considering that the manufacturing technology of radiators for JOHN DEERE tractors is the same, the proposed restoration method may cover the entire volume of these and similar parts.
\end{abstract}

Keywords: recovery efficiency, aluminum radiator, gas-dynamic spray technology, optimum process parameters, economic efficiency, technologies.

\section{Introduction}

Operation of machines is impossible without manifestation of processes of moral and physical aging, the result of which is the fall of technical and economic indicators when using them.

The difficult economic situation in the country and in the world, the fall in the ruble exchange rate, as well as a significant increase in the prices of imported and domestic agricultural machinery, deprive most businesses of the possibility of acquiring new machines. As a consequence, the aging of the machine and tractor fleet is observed, which leads to a loss of the working capacity, increase in the number of failures and increase in economic losses due to the idle time of expensive equipment.

Therefore, at the moment, the issue of rational management of the technical condition of machines is coming to the fore, which can be realized by improving the maintenance and repair processes. However, with the growth of the book value of agricultural machinery, the cost of repair is also growing substantially. This is also facilitated by a significant increase in the prices for spare parts.

The way out of the situation can be to provide the agro-industrial complex with spare parts due to renovation - restoration of worn parts, which allows reusing the residual life of the part, saving significant material, labour, fuel and energy resources. Thus, restoration of worn parts is a significant reserve in saving material and technical resources and increasing the economic efficiency of enterprises.

Previously, the issue of the gas-dynamic recovery method for flat surfaces was considered [1].

\section{Materials and methods}

The experience of joint work of the Belgorod GAO and the enterprises of the technical service of imported equipment made it possible to identify a number of details of the John Deere tractors, which at a relatively high cost having a high failure rate can be restored in the repair enterprise.

One of these parts is the radiator RE226366 of the John Deere 7830 tractor. The radiator consists of thin-walled flat-oval aluminum tubes, rolled into the upper and lower aluminum tanks. In the space between the tubes a honeycomb core of a thin aluminum sheet is mounted.

During the operation of the tractor, due to significant vibrations, there is violation of the tightness of the tubing-tank connections (Fig. 1). 


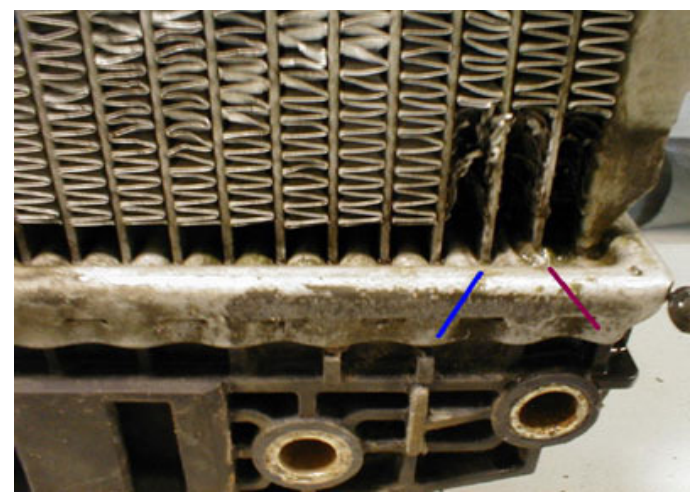

Fig. 1. Seats of leakage failure

The plug of the tubes is technologically impossible. Repair by the use of special sealants added to the coolant is prohibited by the tractor manufacturer, and the use of argon arc welding is difficult due to poor access to the site of leakage and a very small wall thickness (approximately $0.5 \mathrm{~mm}$ ). Therefore, now representatives of the official service center recommend the replacement of the radiator, which, taking into account its cost (Table 1) and the delivery time of the part from a centralized warehouse (from Domodedovo or Europe), adversely affects the efficiency of the tractor operating agricultural enterprise.

Initial data for calculation of economic efficiency (prices of 01.2018)

Table 1

\begin{tabular}{|c|c|c|c|c|c|c|c|}
\hline $\begin{array}{l}\text { Name } \\
\text { Details }\end{array}$ & 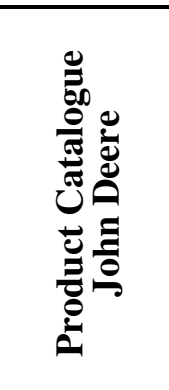 & 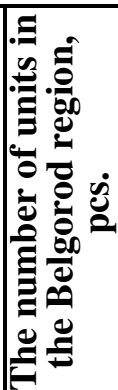 & 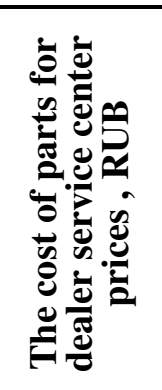 & 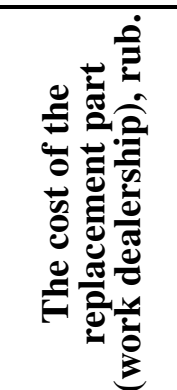 & 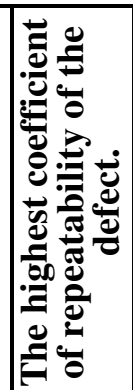 & 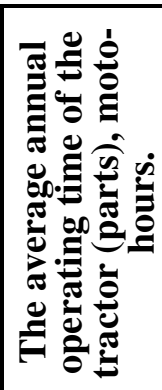 & 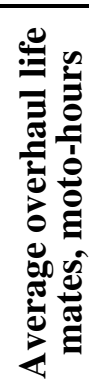 \\
\hline $\begin{array}{c}\text { Tractor radiator } \\
\text { John Deere } 7830\end{array}$ & RE226366 & 191 & 96271.00 & 103471.00 & 0.85 & 1200 & 6000 \\
\hline
\end{tabular}

Thus, the research task is development of a technology for restoration of the radiator RE226366 of the John Deere 7830 tractor and confirmation of the economic efficiency of this process. The solution of the task was carried out in the following order:

- choosing the method of restoring the working capacity of the part and determining its applicability for a detail of the radiator type RE226366 of the JOHN DEERE 7830 tractor;

- determination of the parameters of the technological process ensuring the maximum life of the restored part;

- calculation of the cost-effectiveness of the radiator RE226366 recovery.

As a method of repairing the details of the radiator RE226366 of the John Deere 7830 tractor, it is proposed to use the method of supersonic gas-dynamic spraying [2]. This method of forming coatings due to the high kinetic energy of unmelted metallic particles is now widely known in the world as "cold sputtering". Powder material, which is in a solid state, is accelerated by a supersonic gas stream to a velocity of 500-800 $\mathrm{m} \cdot \mathrm{s}^{-1}$ and is directed to the surface to be reconstructed. Faced with the surface in the process of high-speed impact, the particles are fixed on it, forming a continuous coating. For the experimental verification, the DYMET-405 gasdynamic deposition unit was used [3].

On the heat sink from the tubes for $45-50 \mathrm{~mm}$, the honeycomb filler was removed to access the nozzle of the installation to the place of depressurization. Along the contact line the "tube-tank" was sprayed with powder A-10-01, containing particles of commercially pure aluminum and corundum [4], a layer 1.5-2.5 mm thick. As a result, the place of depressurization was closed with a continuous layer of aluminum, having a hardness of up to $63 \mathrm{~kg} \cdot \mathrm{mm}^{-2}$. Checking the tightness of the radiator in the pool 
under the internal overpressure of $20 \mathrm{kPa}$ showed that the leak in the place of attachment of the tubes to the radiator tank disappeared.

Thus, the applicability of the gas-dynamic spraying method for restoring the defect of the radiator RE226366 of the JOHN DEERE 7830 tractor has been proved experimentally.

Tests in the pool, in addition to confirming the possibility of sealing the radiator joints, revealed the negative properties of this method. In some places, where the layer of the sprayed material is adjacent to the flat-oval tube, new places of leakage have appeared. A detailed visual examination at the magnification showed that there were formed through holes, caused by the abrasive action of the jet of air with the deposited material.

It is known from the literature [5] that the optimum angle for sputtering is $85-90^{\circ}$. If the nozzle is positioned with respect to the surface at an angle of less than $75^{\circ}$, the adhesion of the powder to the workpiece is markedly deteriorated and a strong abrasive wear of the surface, on which the material is sprayed, is observed.

When processing the radiator, because of the difficult access to the remote part of the joint "tubetank", the angle of the nozzle to the surface being sprayed was close to or less than critical. Therefore, it was necessary to conduct a research to identify the process parameters of the sputtering process (the angle of nozzle installation and the distance from the cut of the nozzle to the surface), which makes it possible to obtain a high-quality coating without damaging the walls of the radiator tubes.

Having carried out a series of experiments, it was established that the optimal parameters of the technological process are the distance from the nozzle cut to the sample 6-8 $\mathrm{mm}$ at an angle of $80 \ldots 82^{\circ}$. At the same time, proceeding from the established optimal parameters of the technological process, it is necessary to remove at least $70 \mathrm{~mm}$ of the honeycomb core from the tubes.

Consultations with service specialists confirmed that such removal of the honeycomb aggregate will not have a noticeable effect on the efficiency of the radiator.

The carried out restoration of the radiator with the parameters established in the course of the studies showed complete elimination of failure and renewal of its operative state [7-9].

\section{Results and discussion}

The calculation of the economic efficiency of the recovery is carried out according to the procedure [6;7]:

$$
E f=\left[\left(C_{1}+E_{N} \cdot K_{1}\right) \cdot \frac{P_{1}+E_{N}}{P_{2}+E_{N}}-\left(C_{2}+E_{N} \cdot K_{2}\right)\right] \cdot A_{2},
$$

where $C_{1}, C_{2}$ - cost price of restoration according to the existing and proposed technological processes, respectively, RUB·detail ${ }^{-1}$;

$K_{1}, K_{2}$ - specific capital investments for acquisition and installation of repair and technological equipment for the existing and proposed technological processes, respectively, RUB $\cdot$ detail $^{-1}$;

$E_{N}$ - normative coefficient of efficiency of capital investments, $E_{N}=0.15$;

$P_{1}, P_{2}$ - inverse of the service life of the interfaces restored by the existing and proposed technological processes, respectively;

$A_{2}$ - annual volume of restoration of parts according to the proposed technological process, pcs.

For the basic version we accept the replacement of the radiator with a new one in the dealer service center.

In determining the economic efficiency the following mode of operation of the research and the production laboratory for restoration of the worn parts of the Belgorod SAU was adopted: the number of working shifts is 1 shift, shift duration is 8 hours, number of working days in a week is 5 days, working week is 40 hours, number of working days a year is 250 days and the duration of leave is 24 working days. 
The annual program for restoration of the radiators of John Deere 7830 tractors according to the proposed variant and the base one is unchanged and equal to

$$
A=N \cdot K_{\max }^{R},
$$

where $N$ - number of units of equipment having similar structural elements in the territory serviced by the dealer service center, pcs;

$K_{\max }^{R}$ - highest coefficient of the frequency of the defect.

The annual program for restoration of radiators for $\mathrm{N}=191$ and $K_{\max }^{R}=0.85$ is $\mathrm{A}=162$ pcs.

The values inverse to the service life of the conjugations with the renewed resource are replaced by the new part and the restored one is determined from the relationships:

$$
P_{1}=\frac{T_{1}}{W_{1}}, P_{2}=\frac{T_{2}}{W_{2}},
$$

where $W_{1}, W_{2}$ - average overhaul resources of interfaces with a new part and with a part restored according to the proposed variant.

For the new and restored parts, the average annual operating time is $T=1200$ moto-hours.

The average overhaul resources of conjugations according to the basic variant and restored by the proposed technology are equal $W_{1}=6000$ moto-hours, $W_{2}=3000$ moto-hours. Then $P_{1}=0.2, P_{2}=0.4$.

The cost of the new part is equal to the selling price of the dealer service center $C_{1}=96271$ RUB. The cost of radiator recovery is determined by the formula:

$$
C=C_{z p}+C_{m}+C_{t z}+C_{e l}+C_{a}+C_{z}+C_{p},
$$

where $C_{z p}$-wages of production workers, RUB;

$C_{m}-$ cost of materials, RUB;

$C_{t z}-$ transport and procuring expenses, RUB;

$C_{e l}$ - energy costs, RUB;

$C_{a}$ - cost of depreciation, RUB;

$C_{z}$ - factory expenses, RUB;

$C_{p}$ - other deductions, RUB.

Wages of production workers are defined as:

$$
C_{z p}=C_{b a z}+C_{d o p}+C_{n z p},
$$

where $C_{b a z}$ - basic wages of industrial workers, RUB;

$C_{d o p}$ - additional wages, RUB;

$C_{n z p}-$ accruals for labour payment, RUB.

Calculation of the basic wages for the proposed technological process was carried out based on the time norms for performing operations and the minimum possible tariff rate of the worker:

$$
C_{b a z}^{2}=C_{t s}^{2} \cdot T_{p}^{2} \cdot K_{T},
$$

where $C_{t s}^{2}$ - hourly rate of the work performed, RUB $\cdot \mathrm{h}^{-1}$;

$T_{p}^{2}$ - unit time for restoration of one part, $\mathrm{h}$;

The minimum hourly rate of the first category is determined based on the minimum wage (SMIC), which is established by law and is currently 11163 RUB.

$$
C_{t s}^{2}=\frac{S M I C}{F_{n w t}},
$$

where $F_{n w t}-$ maximum monthly nominal working time fund, equal to 192 hours. 
Then we get 58.14 RUB per hour. For the proposed technological process, all works are performed by workers of the fourth and fifth categories, for which the hourly rate is 136.63 RUB per hour. The unit time for restoration of one part is 72 minutes, then the basic wage is 163.95 RUB.

Additional wages are calculated:

$$
C_{d o p}=C_{b a z} \cdot 0.1 \text {, }
$$

Deductions for social needs are calculated by the formula:

$$
C_{n z p}=0.302\left(C_{d o p}+C_{b a z}\right),
$$

When $C_{z p}^{2}$ is 234.81 RUB.

The cost of materials is calculated by the expression:

$$
C_{m}=\sum M_{i} \cdot C_{i}
$$

where $M_{i}$ - material consumption, $\mathrm{kg}$;

$C_{i}-$ cost of materials used, RUB.

The time of application of the compensating layer to one part, based on the deposition rate of $1.34 \mathrm{~g} \cdot \mathrm{min}^{-1}$, is 72 minutes. The consumption of compressed air during restoration of one part at a feed rate of $0.45 \mathrm{~m}^{3} \cdot \mathrm{min}^{-1}$ for the above period is $32.4 \mathrm{~m}^{3}$. With a compressor capacity of $100 \mathrm{~m}^{3} \cdot \mathrm{h}^{-1}$, the cost of compressed air is $4.85 \mathrm{RUB} \cdot \mathrm{m}^{-3}$. The amount of costs for materials during restoration of the radiator, including the cost of sprayed powder, detergent and compressed air will be 234.14 RUB for one product.

The average cost of a new radiator at prices in 2018 is: $C_{1}=96271$ RUB. Then the residual value of one product is $2888.13 \mathrm{RUB}$, and transport and procurement costs amount to $3465.75 \mathrm{RUB}$. The applied technological equipment for the existing and proposed methods is given in Table 2.

Equipment used in the technological process of restoration

\begin{tabular}{|c|c|c|c|}
\hline Name of equipment & Quantity, pcs. & Power, $\mathbf{k W}$ & Unit cost, RUB \\
\hline DYMET-405 kit & 1 & 3.3 & 276120.00 \\
\hline Compressor & 1 & 10.7 & - \\
\hline
\end{tabular}

Thus, the cost of equipment in the basic and proposed technological processes: $C_{0}^{1}=0$ RUB, $C_{0}^{2}=276120.00$ RUB.

Power consumers: $P_{2}=14 \mathrm{~kW}$.

The cost of electricity for one component is calculated by the formula

$$
C_{e l}=\frac{P \cdot P_{e l} \cdot K_{s} \cdot T_{p}}{A}
$$

where $P$-capacity of power consumers of electric power, $\mathrm{kW}$;

$P_{e l}-$ cost of $1 \mathrm{~kW}$ of electricity, RUB $(\mathrm{kWh})^{-1}\left(P_{e l}=4.50 \mathrm{RUB} \cdot(\mathrm{kWh})^{-1}\right)$;

$T_{p}$ - average annual electricity consumption, $\mathrm{h}\left(T_{p}=0.83 \mathrm{~h}\right)$;

$K_{s}$ - coefficient that takes into account the loading and efficiency of the power equipment $(K=0.75)$.

We get 39.22 RUB;

The cost of depreciation is calculated by the formula:

$$
C_{a}=\frac{0.08 \cdot C o}{A},
$$

where $C_{o}$ - book value of equipment, RUB.

We get 115.10 RUB. 
We accept the general factory expenses in the amount of $350 \%$.

$$
C_{z}=3.5 \cdot C_{z p},
$$

Then factory deductions for the proposed technological process will amount to $C_{z}^{2} 383.50$ RUB. Other deductions are calculated by the formula:

$$
C_{p}=0.15 \cdot C_{M},
$$

Then for the existing and proposed technological processes other deductions will amount to $C_{p}$ 35.12 RUB. Specific capital investments are calculated as:

$$
K=\frac{C_{b}}{A_{2}}
$$

To compare the economic efficiency of capital investments, we calculate the indicator of the minimum of the given costs by the formula:

$$
C_{i}+E_{N} \cdot K_{i} \rightarrow \min
$$

We calculate the economic feasibility of repair by the formula:

$$
\frac{C_{N}-\mathrm{C}_{\mathrm{os} t}}{T_{N}} \geq \frac{C_{p}+E_{N} \cdot K_{y}}{T_{p}},
$$

We get $15.5>>1.7$. Since the inequality condition is satisfied, the restoration of the radiator can be considered economically feasible. Provided that the $50 \%$ maintenance of the resource is provided (instead of 6000 moto-hours - 3000 moto-hours), the purchase of the restored part is 4 times more economical than the new one.

\section{Conclusions}

Thus, the conducted research has established that the use of the supersonic sputtering unit for restoration of the aluminum radiator RE226366 of the JOHN DEERE 7830 tractor makes it possible to fully restore the workability of the part with high profitability and a payback period of additional capital investments of 0.33 years. Given that the technology of manufacturing radiators of the JOHN DEERE machinery is the same, the proposed technology can cover the entire volume of these parts and not only.

\section{References}

[1] Strebkov S., Turyanskiy A., Bondarev A., Slobodyuk A. Economic evaluation of recovery of parts of foreign equipment by gas-dynamic spraying // 17th International Scientific Conference Engineering For Rural Development Proceedings. May 23-25, 2018. 2018. Volume 17. pp.1334-1345.

[2] Продукция ДИМЕT (Products DIMET®) [online] [15.01.2018]. Available at: http://www.dimet.info/products/ (In Russian)

[3] Установка для напыления металла DYMET 405 (Installation for spraying metal DYMET 405) [online]. [15.01.2018]. Available at: http://regionfox.ru/katalog/oborudovanie-dlya-napyleniyametalla/ustanovka-dlya-napyleniya-metalla-dymet-405 (In Russian)

[4] Price list of equipment and supplie [online]. [15.01.2018]. Available at: http://www.dimet.info/price/

[5] Dikun Yu.V, Zemskov V.A. The use of gas-dynamic coating to improve the operational performance parts. Strengthening technology and coatings, - 2005, No 10, pp. 15-17

[6] Шпилько А.В. Руководство по подготовке бизнес-планов по внедрению технологий и сельскохозяйственной техники (Guidelines for the preparation of business plans for the introduction of technologies and agricultural machinery). Moscow: VNIIESKH, 2008, 40 p. (In Russian) 
[7] Стребков С.В., Слободюк А.П. Оценка эффективности импортозамещения запасных частей для сельскохозяйственной техники (Efficiency assessment of import substitution of agricultural machinery spare parts) Challenges and opportunities of innovative development of agrotechologies, Materials of the XIXth International scientific and production conference, 2426 May 2015, Belgorod, Russia. (In Russian)

[8] Стребков С.В., Слободюк А.П. Восстановление работоспособности деталей импортной сельскохозяйственной техники (Restoration of working capacity of parts of foreign agricultural machinery). Materials of the International distance research and practice conference «Important directions of scientific investigations of the XXIth century: theory and practice»: collection of research papers, Voronezh, Russia, 5 (2014), pp.268 $\square$ 272. (In Russian)

[9] Стребков C.В., Слободюк А.П. Восстановление деталей импортной техники (Recovery of components imported machinery). Moscow, Proceedings GOSNITI. - 2014 - T.117, ch. 1. (In Russian) 